\title{
Statistical Analysis of Ionization Energy Correlations and of Integral Quantum Characteristics in the Series of Anthraquinone Derivatives
}

\author{
Michel Yu. Dolomatov ${ }^{1} \&$ Ella A. Kovaleva ${ }^{2}$ \\ ${ }^{1}$ Department of Physics, Ufa State Academy of Economics and Service, 145 Chernyshevskiy St., Ufa, Russian \\ Federation \\ ${ }^{2}$ Department of Mathematics, Ufa State Petroleum Technological University, 1 Kosmonavtov St., Ufa, Russian \\ Federation \\ Correspondence: Ella A. Kovaleva, Department of Mathematics, Ufa State Petroleum Technological University, 1 \\ Kosmonavtov St., Ufa 450062, Russian Federation. E-mail: Kovaleva-ugntu@yandex.ru
}

Received: January 21, 2013 Accepted: February 16, 2013 Online Published: March 20, 2013

doi:10.5539/apr.v5n2p42 URL: http://dx.doi.org/10.5539/apr.v5n2p42

\begin{abstract}
The classes of anthraquinone derivatives, containing $\mathrm{OC} 6 \mathrm{H} 4 \mathrm{C}\left(\mathrm{CH}_{3}\right)_{3}$ and $\mathrm{NC}_{5} \mathrm{H}_{10}$ groups have been investigated. Quantum-chemical calculations with the help of semiempirical method PM3 and absorption spectra in the visible and UV-areas have been carried out. With the use of single factor regression and correlation analysis, the linear correlations between the vertical ionization potentials and the integral strength of the oscillator have been ascertained. This fact indicates strong electron correlation between the highest and the low electron levels of molecules. The errors for the ionization potentials have been calculated.
\end{abstract}

Keywords: anthraquinone derivatives, electron absorption spectra, vertical ionization potentials, integral strength of the oscillator, correlations

\section{Introduction}

The urgency of the research in the sphere of anthraquinone and its derivatives chemistry is defined not only by the problems of synthetic organic chemistry, that is creating of new reactions, developing of new methods of synthesis, specific synthesis of new organic compounds, which have the defined physical, chemical and biological characteristics, which are important for practical use, but by the problems of theoretical organic chemistry as well (Bien, Stawitz, \& Wunderlich, 2005). From the theoretical point of view the investigation of anthraquinone and its derivatives chemistry is important for understanding of the laws of chemical reactions in the course of which donor-acceptor complexes are formed.

The aim of the research is the ascertainment of the compounds of the integral oscillator strength (IOS, m) with the ionization potentials (IP, eV) among the anthraquinone containing derivatives 1-(4-tert-butylphenoxy) group $\mathrm{OC}_{6} \mathrm{H}_{4} \mathrm{C}\left(\mathrm{CH}_{3}\right)$.

\section{Methods of Calculating}

In the basis of the investigated compounds there is oxidized forms, which is the derivative 9,10-anthraquinone. For the realization of the task assigned we conducted quantum-chemistru calculations. As a rule, for organic molecules the assessment of vertical IP in the frame of Koopman's theory in approximation of hartree - Fock orbital. The values of IP were defined with the help of Koopman's theory, according to which the values of IP are not calculated directly, but represent energy taken with the opposite sign (eigenvalue) of the molecular orbital (MO) with the number of the upper occupied molecular orbital (UOMO) (Clark, 1990). In the capacity of electron-exchange characteristics in the investigated bonds estimate, semiempirical method of computer quantum-chemical calculation PM3 with the full optimization of the geometry of molecules was applied. Donor characteristics of the molecules were defined by the energy characteristics of the upper occupied molecular orbital (UOMO), with the energy value of which the vertical potential of ionization was calculated. The integral strength of the oscillator was calculated from the spectra of aromatic and heterocyclic compounds absorption. The electron spectra of absorption were defined in ethyl alcohol in ultraviolet and visible areas and were presented in the coordinates $\lg \varepsilon \div \lambda(\mathrm{nm})$, where $\lambda(\mathrm{nm})$ is the wavelength, lg $\varepsilon$ is the logarithm of molar absorption indicator (the logarithm of the extinction coefficient) (Clark, 1990). Firstly, for a series of simple 
molecules the correlated dependence among ISO, the ionization energy and the affinity with the electron (Coptug, 1978; Dolomatov, 1995; Dolomatov \& Mukaeva, 1995):

$$
I P=\alpha+\beta \Theta
$$

were obtained, where $\alpha, \mathrm{eV}$ и $\beta, \mathrm{eV} / \mathrm{nm}$ are constants, $\Theta$ is the integral strength of the oscillator, $\mathrm{nm}$.

$$
\Theta=\int_{\lambda_{0}}^{\lambda_{k}} \lg \left(\varepsilon_{\lambda}\right) d \lambda
$$

In our research the integral strength of the oscillator represents experimentally defined area under the absorption line. Let us define more precisely the notion of the logarithmic ISO. Electron absorption spectra were detected in ultraviolet and visible areas in the coordinates $\lg \varepsilon \div \lambda(\mathrm{nm})$, where $\lambda(\mathrm{nm})$ is the wavelength, lg$\varepsilon$ is the logarithm of the molecular absorption indicator (the logarithm of the extinction coefficient) (Eleshevich, 2001). As it is known, for the simplification of calculations $\lg \varepsilon$ is often used in ultraviolet and visible spectroscopy because it allows with the equal accuracy to render the form of spectral stripes, which are different in intensity in several values (Burshtein \& Shorygin, 1989). Because of the fact that the logarithm is the dimensionless quantity, the converted dimension quantity was turned into dimensionless before finding the logarithm. In our investigations the integral strength of the oscillator represents experimentally defined area under the absorption line. Apparently ISO, calculated according to the logarithmic Formula (2) characterizes the scale of the quantum system of the quantum continuum which interacts with radiation. The processing of the results was realized according to the algorithm of single factor regression and correlation analysis. As in the general case the exact analytical dependence of IP from ISO is not known, it is reasonable to orient to the construction of the correlation model, which takes into account the peculiarities of carrying out laboratory experiments, that is to use the correlation for the search of linear correlations among the characteristics. The criterion of assessing of the calculations accuracy was the average quadratic error (AQE) of measurement, which was calculated according to Gauss formula.

Numeric differences in the ionization potentials, calculated with the help of the method PM3 and according to the trendline, was defined with the help the statistic of Fisher's (F-test) according to the formula: $F=\frac{S_{P I}^{2}}{S_{P I^{*}}^{2}}$, where $S_{P I}^{2}$ is the variance of the first group and $S_{P I^{*}}^{2}$ is the variance of the second group.

\section{Results Review}

In the research under consideration we investigated the class of representatives of anthraquinone derivatives with the substituents $\mathrm{OC}_{6} \mathrm{H}_{4} \mathrm{C}\left(\mathrm{CH}_{3}\right)_{3}$ (Table 1) and constructed the correlation dependencies of IP from ISO (Figure 1), as well as calculated the calculation errors.

Explanations of the Table:

PI, eV - the potentials of ionization calculated by method PM 3;

$\mathrm{PI}^{*}, \mathrm{eV}$ - the potentials of ionization calculated on a line of a trend;

$\delta$, эВ - absolute error; $\Delta, \%$ - ratio error 
Table 1. The anthraquinone compounds containing 1-(4-tert.-butylphenoxy) group

\begin{tabular}{|c|c|c|c|c|c|c|}
\hline No & The name and the chemical formula & $\begin{array}{l}\text { ISO } \\
\mathrm{nm}\end{array}$ & $\begin{array}{l}\text { PI } \\
\mathrm{eV}\end{array}$ & $\begin{array}{l}\mathrm{PI}^{*} \\
\mathrm{eV}\end{array}$ & $\begin{array}{c}\Delta \\
\text { эB }\end{array}$ & $\begin{array}{l}\Delta \\
\%\end{array}$ \\
\hline 1 & $\begin{array}{l}\text { 1-(4-tert.- butylphenoxy)antraguinone } \\
\qquad \mathrm{C}_{24} \mathrm{H}_{20} \mathrm{O}_{3}\end{array}$ & 375 & 9,45 & 9,46 & 0,01 & 0,07 \\
\hline 2 & $\begin{array}{l}\text { 2-nitro-1-(4- tert.- butylphenoxy)antraguinone } \\
\qquad \mathrm{C}_{24} \mathrm{H}_{19} \mathrm{NO}_{5}\end{array}$ & 669 & 9,16 & 9,16 & 0,00 & 0,02 \\
\hline 3 & $\begin{array}{l}\text { 1-(4- tert.- butylphenoxy) -2-oxyantraguinone } \\
\qquad \mathrm{C}_{24} \mathrm{H}_{20} \mathrm{O}_{4}\end{array}$ & 540 & 9,32 & 9,29 & 0,03 & 0,31 \\
\hline 4 & $\begin{array}{l}\text { 3-bromine-(4- tert.- butylphenoxy)antraguinone } \\
\qquad \mathrm{C}_{24} \mathrm{H}_{19} \mathrm{BrO}_{3}\end{array}$ & 425 & 9,38 & 9,41 & 0,03 & 0,28 \\
\hline 5 & $\begin{array}{l}\text { 2-acetylamino-1-(4- tert.- butylphenoxy)antraguinone } \\
\qquad \mathrm{C}_{26} \mathrm{H}_{23} \mathrm{NO}_{4}\end{array}$ & 444 & 9,36 & 9,39 & 0,03 & 0,29 \\
\hline 6 & $\begin{array}{l}\text { 2-triftoracetylamino-1-(4- tert.- butylphenoxy)antraguinone } \\
\qquad \mathrm{C}_{26} \mathrm{H}_{20} \mathrm{~F}_{3} \mathrm{NO}_{4}\end{array}$ & 469 & 9,39 & 9,36 & 0,03 & 0,30 \\
\hline 7 & $\begin{array}{l}\text { 2-isobutyrylamino-1-(4- tert.- butylphenoxy)antraguinone } \\
\qquad \mathrm{C}_{28} \mathrm{H}_{27} \mathrm{NO}_{4}\end{array}$ & 435 & 9,35 & 9,40 & 0,05 & 0,49 \\
\hline 8 & $\begin{array}{l}\text { 2-benzoilamino-1-(4- tert.- butylphenoxy)antraguinone } \\
\qquad \mathrm{C}_{31} \mathrm{H}_{25} \mathrm{NO}_{4}\end{array}$ & 463 & 9,30 & 9,37 & 0,07 & 0,73 \\
\hline 9 & $\begin{array}{l}\text { 2-(4-nitrobenzoil)amino-1-(4- tert.- butylphenoxy)antraguinone } \\
\qquad \mathrm{C}_{31} \mathrm{H}_{24} \mathrm{~N}_{2} \mathrm{O}_{6}\end{array}$ & 479 & 9,36 & 9,35 & 0,01 & 0,08 \\
\hline 10 & $\begin{array}{l}\text { 2-(pentaftorbenzoil)amino-1-(4- tert.- butylphenoxy)antraguinone } \\
\qquad \mathrm{C}_{31} \mathrm{H}_{20} \mathrm{~F}_{5} \mathrm{NO}_{4}\end{array}$ & 455 & 9,37 & 9,38 & 0,01 & 0,07 \\
\hline 11 & $\begin{array}{l}\text { 2-methylamino-1-(4- tert.- butylphenoxy)antraguinone } \\
\qquad \mathrm{C}_{25} \mathrm{H}_{23} \mathrm{NO}_{3}\end{array}$ & 630 & 9,11 & 9,20 & 0,09 & 0,99 \\
\hline 12 & $\begin{array}{l}\text { 4-(N-acetyl-N-methylamino)-1-(4-tert.-butylphenoxy)antraguinone } \\
\qquad \mathrm{C}_{27} \mathrm{H}_{25} \mathrm{NO}_{4}\end{array}$ & 386 & 9,47 & 9,45 & 0,02 & 0,26 \\
\hline 13 & $\begin{array}{l}\text { 2-dibenzilamino-1-(4- tert.- butylphenoxy)antraguinone } \\
\qquad \mathrm{C}_{38} \mathrm{H}_{33} \mathrm{NO}_{3}\end{array}$ & 581 & 9,27 & 9,25 & 0,02 & 0,21 \\
\hline 14 & $\begin{array}{l}\text { 3-piperidin-1-(4- tert.- butylphenoxy)antraguinone } \\
\qquad \mathrm{C}_{29} \mathrm{H}_{29} \mathrm{NO}_{3}\end{array}$ & 654 & 9,12 & 9,18 & 0,06 & 0,62 \\
\hline 15 & $\begin{array}{l}\text { 1-hydroxy-2-(4- tert.- butylphenoxy)antraguinone } \\
\qquad \mathrm{C}_{24} \mathrm{H}_{20} \mathrm{O}_{4}\end{array}$ & 532 & 9,34 & 9,30 & 0,04 & 0,44 \\
\hline 16 & $\begin{array}{l}\text { 2-diethylamino-1-(4- tert.- butylphenoxy)antraguinone } \\
\qquad \mathrm{C}_{28} \mathrm{H}_{29} \mathrm{NO}_{3}\end{array}$ & 690 & 9,04 & 9,14 & 0,10 & 1,11 \\
\hline 17 & $\begin{array}{l}\text { 4-methylamino-1-(4- tert.- butylphenoxy)antraguinone } \\
\qquad \mathrm{C}_{25} \mathrm{H}_{23} \mathrm{NO}_{3}\end{array}$ & 675 & 9,18 & 9,16 & 0,02 & 0,26 \\
\hline & Average errors & & & & 0,04 & 0,38 \\
\hline & Root-sum-square uncertainty, eV & & & & & \\
\hline
\end{tabular}


It indicates, that the differences, which take place in the calculations of IP are insignificant and the trendline describes well the dependence of IP from ISO.

$\mathrm{F}$ is the ratio of two variances. The F-test statistic (rounded to two decimal places) is $\mathrm{F}=1,39$. For $\mathrm{F}(16,16)$ and a probability of 0,05 , the $\mathrm{F}$ statistic is 2,33 .

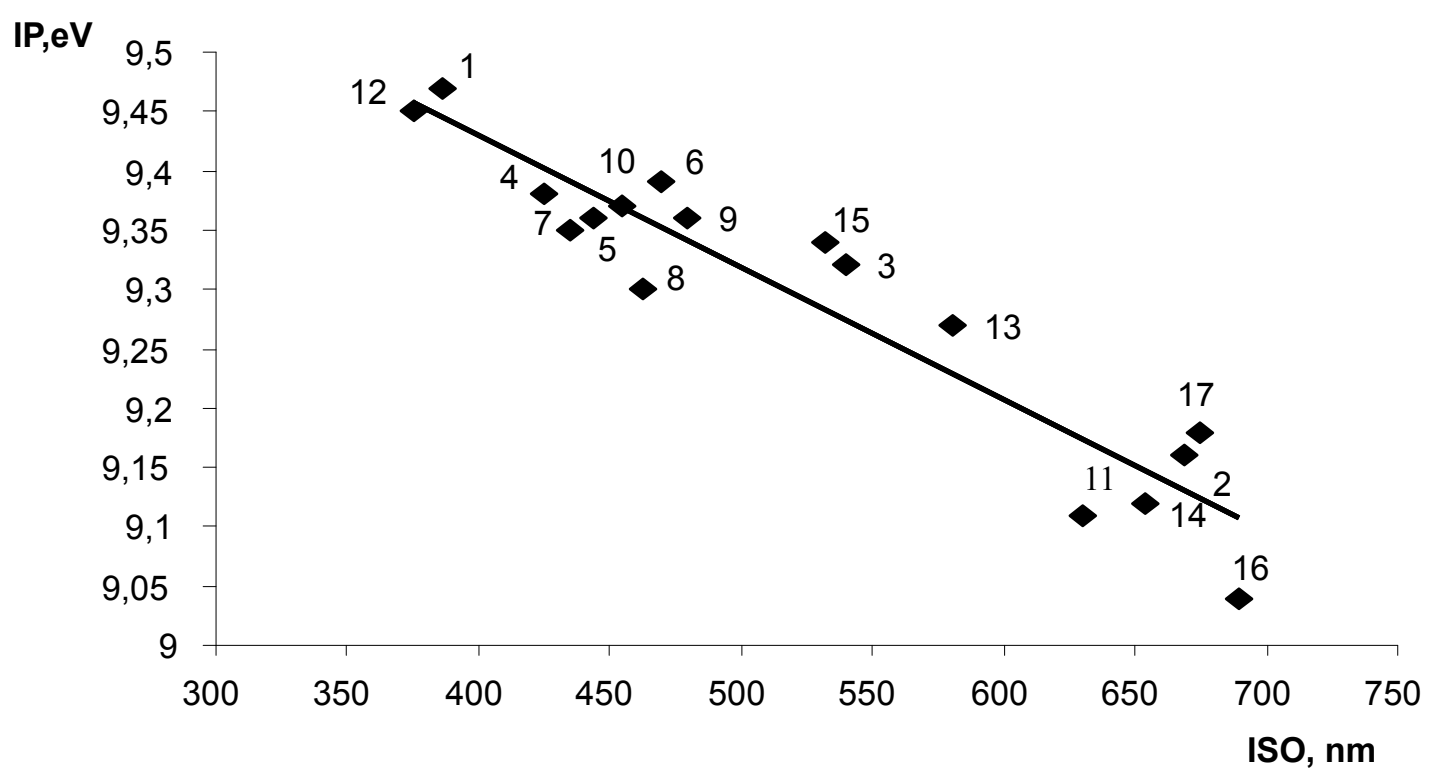

Figure 1. The dependence of the ionization potentials on the integral strength of the oscillator in a series of anthraquinone derivatives with the substituents $\mathrm{OC}_{6} \mathrm{H}_{4} \mathrm{C}\left(\mathrm{CH}_{3}\right)_{3}$

The points on the diagram form the area which is alike a straight line. It indicates the existence of close positive correlation among the variables under consideration. The scatter plot below shows a linear regression line superimposed on it. It also displays the value of $\mathrm{R}^{2}$ and the equation of the line. Regression Equation $y=-0.0011 x+9.8727$. Observe that the $y$-intercept value is 9.8727 and the value of the slope is $-0.0011 . R^{2}$ demonstrates the degree of the trend approximation to the actual values of the dynamical series. As the figure shows, these IP and ISO have close to linear dependence. The value of approximation reliability equals to 0,89 . This indicates good coincidence of the calculation line with the data. On the assumption of all the above said we can make a conclusion that this linear dependence is quite applicable for defining of ISO with the help of IP and vice-versa. We should mention that the pattern of observance does not fit in with the known dependence of IP on ISO. Apparently, it is connected with the entropic effects because of great number of substituents in these molecules.

\section{Conclusions}

The analysis of the available experimental data and quantum-chemical calculations confirm the correlation of ISO with vertical IP for anthraquinone derivatives, which contain 1-(4-tert-butylphenoxy) group (substituents of $\left.\mathrm{OC}_{6} \mathrm{H}_{4} \mathrm{C}\left(\mathrm{CH}_{3}\right)_{3}\right)$, which was ascertained earlier for simpler compounds. The linear connection between the vertical ionization potential and the integral strength of the oscillator was determined. It indicates strong correlation interaction of the electrons of the highest and low electron levels of the molecules.

\section{References}

Atlas of spectra of aromatic and heterocyclic compounds. (1978). Edition 16/Academy of sciences of USSR, Siberian branch. Novosibirsk institute of organic chemistry. Scientific-information center on molecular spectroscopy. Under the reduction of V.A. Coptug. Novosibirsk NIOC, p. 162.

Bien, H.-S., Stawitz, J., \& Wunderlich, K. (2005). Anthraquinone Dyes and Intermediates. Ullmann's Encyclopedia of Industrial http://doi.ox.org:10.1002/14356007.a02_355 
Burshtein, K. Ya., \& Shorygin, P. N. (1989). Quantum and Chemical Calculations in Organic Chemistry and Molecular Spectroscopy (p. 104). Nauka.

Clark, T. (1990). Computational chemistry. In Tin Clark (Ed.), A Handbook of Computational Chemistry(p. 383), 1985. John Wiley \& Sons, Inc.

Dolomatov, M. Yu., \& Mukaeva, G. R. (1995). The application of phenomenological electronic spectroscopy for investigation of physical and chemical characteristics of molecular systems. Refining and petrochemicals (Refining and petrochemicals), 5(6), 22-26.

Dolomatov, M. Yu. (1995). Application of electronic phenomenological spectroscopy for identification and investigation of compound organic systems. Chemistry and Technology of Fuels and Oils, 1, 29-32.

Eleshevich, M. E. (2001). Atomic and Molecular Spectroscopy (2nd ed., p. 896). URSS. 